\title{
The Main Aspects of the Exercises Use Fulfilled in Static-Dynamic Regime in the Training Process of Rowers
}

\author{
Zub I.V. \\ Admiral S.A. Makarov State University of Sea \\ and River Fleet \\ Saint-Petersburg, Russia \\ zubiv@mail.ru
}

\author{
Bykov A.V. \\ Admiral S.A. Makarov State University of Sea \\ and River Fleet \\ Saint-Petersburg, Russia \\ 9155431@mail.ru
}

\author{
Kurys V.A. \\ Admiral S.A. Makarov State University of Sea and River Fleet \\ Saint-Petersburg, Russia \\ kuris@mail.ru
}

\begin{abstract}
The increasing demands placed on the athletes, who specialize in rowing, lead to the necessity to search for new means and methods of the training process. Classical distance for rowing is $\mathbf{2 0 0 0}$ meters. The result of the distance overcoming is an integral index, which depends on rowing technique, rower's physical and psychological readiness and also on external factors. Competitive activity in rowing happens in the zone of submaximal power. It has maximal physiological shifts. Because of oxygen debt the activity of nervous centers is realized in terms of oxygen deficiency and it leads to tiredness. Knowing the mechanisms of tiredness helps to plan the training process rationally. The training loads increase doesn't always give a positive result, in some cases it leads to overtraining state. Success during the competitions in rowing happens owing to athlete's developed strength oriented qualities. On the basis of strength oriented qualities speed-power endurance is developed, without which a rower won't be able to hold the speed of the boat during the competitive distance. Classical variant of strength oriented qualities development is the work with maximum weight of the poundage. The offered method of the exercises fulfillment in static-dynamic regime in order to develop strength oriented qualities is less dangerous for an athlete and slow, in terminal points static regime of fulfillment provides muscle ligaments strengthening.
\end{abstract}

Keywords-rowing; endurance; strength-oriented qualities; static-dynamic exercises.

\section{INTRODUCTION}

The increasing demands placed on the training and competitive activity of rowers and their functional readiness lead to the training loads increase, which not always means positive results. Competitive results in rowing depend on environmental conditions, technical state of the boat, physical and psychological readiness of athletes. If we consider each factor, a coach can influence technical, physical and psychological training of an athlete. As a rule, psychological training happens together with physical one.
The greatest volume has physical training. Competitive results improvement without considerable training loads increase conditions the necessity to search for new scientifically substantiated means and methods of the training process.

Classical distance for rowing is 2000 meters. During the distance an athlete fulfills almost 240 strokes. The force that a rower exerts on an oar handle is more than $50-70 \mathrm{~kg}$ and at spurt parts the force increases and it helps to preserve high speed of the boat at each stroke. The average time an oar is in the water is $0,7-0,9$ seconds. With the speed increase there is force and energy expenditures increase, which a rower has to realize in order to move the boat, as boat tractive resistance increases in quadratic dependence on speed [1]. The speed of boat movement support is defined by the level of a rower's technical mastery, his physical and functional training level. The technique of a strike depends on many factors, including rower's physical qualities [2]. The main physical quality of a rower is speed-power endurance. The base for speed-power endurance development is athlete's strength oriented qualities development. They have a great influence on the result of competitions [3, 4], as the cycle of a strike is an integral index of the amplitude, tempo and force exerted on an oar handle. The force, multiplied by the length of the handle, gives a moment, which conditions the movement of the boat. One more important factor is a rower's coordination of movements with other members of the team.

\section{LITERATURE REVIEW}

Competitive activity in rowing happens in the zone of submaximal power, where there are maximal physiological shifts [3, 5] and blood circulation disorder [6]. In submaximal power zone only $15-20 \%$ of energy is provided owing to ATP (adenosine triphosphate) and $\mathrm{CrF}$ (creatine phosphate), $55 \%$ owing to glycolysis and $25 \%$ owing to aerobic glucose split. That is why oxygen debt is formed by 
lactate fraction. Lactate formation in an organism happens as a result of anaerobic process of glycolysis [7]. In this zone of power the amount of lactic acid in blood increases and it causes blood $\mathrm{pH}$ and tissues shift towards acid. Lactic acid concentration depends on the following: lack of oxygen in the working muscles; the ability of the working muscles to realize glycolytic energy production; the ability of an organism to utilize lactic acid, which comes from the working muscles into blood [8]. An oxygen debt in the zone of submaximal power is $20-22$ liters. The activity of nervous centers is realized in terms of hypoxia and it leads to tiredness [5, 9]. In the work [5] tiredness is considered as intersystem relations interaction between neurophysiological parameters and morphofunctional peculiarities of quick and slow muscular fibers. In the work [9] the author underlines that tiredness is a normal functional state of an organism in the process of physical loads. Knowing the mechanisms of tiredness will help to control the training process. Different percentage of the muscular fibers types reflects individual abilities of an athlete and his opportunities in different physical qualities development. During the training and competitive loads of rowers, who specialize in rowing, $2 / 3$ of athlete's muscle mass is used [7,10].The training process of rowers is based on strength oriented qualities and power endurance development $[3,11]$.The main stress should be done on power training of muscles, which experience the main load during the distance, as special working capacity of an athlete depends on their power potential [12]. In the work $[13,14]$ authors divide the notions of special and specific endurance and come to the conclusion that special endurance is developed on the basis of specific endurance. It depends on the chosen kind of sport. The training process for endurance development is competitive distance overcoming with the speed. It is $10-15 \%$ lower than the maximum speed and with maximal resources of an organism use [14].

Muscles power increase and speed abilities of athletes improvement is realized by means of speed-power training. The limiting factor in rowing, as well as in other kinds of sport with endurance demonstration, is cardiovascular system (CVC) state. It provides the ability to utilize oxygen with the help of the working muscles $[5,6,8,11,12,15]$. With the maximum stress on dynamic component, there is a distinct left parts of heart dilatation $[12,16,17]$. In order to decrease the level of muscular apparatus tiredness and to increase speed-power qualities in terms of power training creatine is supposed to be used [18].

Biochemical adaptation during the trainings of speed and strength oriented qualities development has the same mechanism. Both in the $1^{\text {st }}$ and the $2^{\text {nd }}$ case there is ATP (adenosine triphosphate) activity of muscles increase, creatine phosphate resynthesis of ATP develops, the amount of contractile protein increases. ATP resynthesis in muscular fibers happens in three ways: creatine phosphokinase reaction, glycolysis and aerobic oxidization of nutrient substances. Creatine phosphokinase reaction is the quickest system of ATP resynthesis in an organism [19]. Creatine phosphokinase activity depends on cellular membranes state and their penetrability change under the influence of physical loads [20].

During strength oriented qualities development biochemical bases are created for speed qualities formation. They depend on the following: intramuscular coordination, intermuscular coordination, physiological diameter of a muscle, quick (QMF) and slow (SMF) muscular fibers ratio, muscles length, mechanical efforts. QMF unlike SMF are characterized by bigger size, high activity of glycolysis ferments, greater contractile force, weak oxidization ability because of smaller amount of mitochondria and quick level of tiredness. SMF have a lot of mitochondria and high oxidization ability, less level of tiredness, smaller size and smaller contractile force. An athlete with high QMF level is inclined to speed-power work and less inclined to high power endurance demonstration. High SMF concentration creates preconditions for more effective work directed toward power endurance.

One more factor, which influences strength oriented qualities development, is physiological diameter of a musclemuscular fibers hypertrophy. Muscles hypertrophy is a slow process. It depends on protein synthesis and split. Systematic power oriented trainings cause adaptation, which leads to muscles hypertrophy owing to muscle cells size increase [21].

In physiological research works, carried out recently, there are 4 main factors, which condition increased protein synthesis in muscular fibers (MF):

1) amino acids stock in a cell;

2) anabolic hormones concentration increase in blood and in a muscle;

3) "free" creatine increase in MF;

4) the increased concentration of hydrogen ions in MF.

The second, third and fourth factors are directly connected with the content of the training exercises. Traditionally in order to develop strength oriented qualities classical training is used. It includes the exercises, which are fulfilled with poundage $70-100 \%$ from a maximum weight. The ability of the muscles to resist tiredness depends on oxidization potential of muscles. They are qualified as oxidative muscular fibers (OMF) and glycolytic muscular fibers (GMF). In OMF mitochondria prevail and lactic acid is almost not formed in them. In GMF the amount of mitochondria is not significant and in terms of their work the amount of lactic acid increases. As a result, there is acidulation and local tiredness.

During classical power work with maximal poundage, which is fulfilled in a dynamic regime, both SMF and QMF are recruited, but only quick ones are trained. Thus, there appears contradiction, SMF work, but there is no effect. The reason for such situation is in the fact, that the most important factor, which increases myofibrils hyperplasia, is the level of anabolic hormones increase (growth hormone, 
testosterone) in blood and then in nuclei of muscle cells. The increased concentration of hydrogen ions, which appeared because of anaerobic processes in muscular fibers during power work fulfillment with maximum poundage, causes pores increase in membranes. It makes hormones penetration into a cell easier. There are a lot of mitochondria in SMF. They absorb hydrogen ions, without muscles oxidation and anabolic hormones can't penetrate into a cell. It leads to conditions absence for myofibrils hyperplasia [17].

As it was already mentioned above, classical power training in a dynamic regime doesn't have developing effect on hyperplasia in SMF [18]. The method of strength oriented exercises fulfillment in static-dynamic regime was offered in the work [12]. In this regime exercises are fulfilled in a slow tempo, with the restricted amplitude of movement, with not big poundage and without relaxation phase. The last condition meeting is necessary, as in terms of relaxation absence in the muscle tense and thickened MF clamp capillaries and it leads to local blood circulation stop. Then appears local hypoxia and it conditions anaerobic glycolysis in SMF, providing lactate and hydrogen ions accumulation.

\section{RESEARCH METHODOLOGY}

The following methodology was used in the research work: scientific literature review and analysis. Literature sources review was held in order to search for modern alternative methods of training in rowing with further received information analysis. The training loads increase leads to physical tiredness and athletes' psychological burnup, that is why nowadays health-improving technologies become more and more urgent.

\section{THE RESULTS}

In order to achieve greater training effect, directed toward strength oriented qualities development, we can offer to fulfill one approach or a supersequence of exercises at the end of the training lesson. These exercises are fulfilled in static-dynamic regime for targeting group of muscles.

During the exercises fulfillment in static-dynamic regime we can underline high degree of the demanded psychic tension, as a result of the necessity to bear muscle pain (burning pain), especially during supersequences fulfillment, which is a negative moment of exercises use in a staticdynamic regime. For endurance oriented kinds of sport it is not bad, even useful, but can be recommended for training highly-qualified rowers, not only as an exercise. It develops strength oriented qualities, but also as a psychological training, which develops volitional qualities of an athlete.

The use of exercises fulfilled in static-dynamic regime, as the means of physical training, is recommended to start from fulfilling the exercise with one approach and great pause of rest, gradually moving to the exercise fulfillment in the regime of a supersequence.

The exercises use in static-dynamic regime is not recommended during training junior teams.

\section{DISCUSSION}

The advantage of the exercises, fulfilled in static-dynamic regime, is their low level of injury risk for an athlete's locomotor apparatus. Maximum recommended load in not higher than $70 \%$ from the maximum. A slow, and in terminal points static, tempo of the exercises fulfillment provides muscular ligaments strengthening.

The exercises use, fulfilled in static-dynamic regime of the average intensity, according to the results of the published research works, fulfilled in a slow tempo, cause great splash of free testosterone and growth hormone in blood, than the exercises of a low and high intensity, fulfilled in an ordinary dynamic regime. The increased concentration of these hormones in blood and muscles is one of the most important conditions for protein synthesis increase in muscular fibers and as a result an athlete's strength oriented qualities development [22].

In case of scientifically substantiated training of rowers, cross-sections of SMF and QMF shouldn't differ. The power of muscular fibers contraction depends on the amount of myofibrils in them and on the cross-sectional areas. In terms of similar section of SMF and QMF there is no failure in some athlete's strength oriented qualities, there is only loss in speed and power of contraction. It is conditioned by higher activity of myosin ATP in QMF. Maximum speed of SMF and QMF contraction differs for $20-40 \%$. The speed of muscular fibers contraction in terms of real competitions is no more than $50 \%$ from maximal speed of a muscle contraction. That is why the power of SMF gives speed and motor action power increase almost in any kind of sport [12, 23]. As demonstrated during rowing efforts, even in terms of starting and finishing speeding-up, are far away from being maximum indices of muscular fibers contraction speed and power, the most effective for rowers is muscular fibers with high oxidative opportunities increase. QMF cross-section increase will not lead to the result improvement at the distance. It leads to the following conclusion: it is important to have training work oriented toward SMF hypertrophy, as the most enduring ones.

\section{CONCLUSION}

The aim of a coach during power training planning should be an optimal physiological diameter of muscular fibers increase and maximal mitochondrial net around them development.

For slow and quick muscular fibers training different methodologies are used. The exercises, fulfilled in staticdynamic regime, together with strength oriented qualities, develop volitional qualities of an athlete, as during the exercises fulfillment an athlete feels pain in muscles. Pain appears as a result of hydrogen ions accumulation. During power exercises fulfillment in static-dynamic regime the number of lifts and a total weight are formal criteria. The main aim of these exercises is to cause the definite physiological and biochemical processes in muscular fibers in each approach.

The recommended amount of trainings in staticdynamic regime for strength oriented qualities development 
[19] Bakhareva A.S., Isaev A.P., Savinykh E.Y., Baymukhametova E.F. Physiological adaptation to great training loads, which develop endurance of athletes. Man, Sport, Medicine. 2016, vol. 1, 1, pp. 29 33. DOI: $10.14529 / \mathrm{hsm} 160105$

[20] Rybina I.L., Kuznetsova Z.M. Creatine phosphokinase activity use in athletes' organism urgent and long-term adaptation estimation to training loads. Pedagogico-pshycological and medico-biological problems of physical culture and sport. 2015, 3(36), pp. $150-158$. DOI 10.14526/01_1111_41.

[21] Astratenkova I.V., Ragozkin V.A. Molecular mechanisms of skeletal muscles hypertrophy. . Russian physiological journal named after I.M. Sechenova. 2014, vol. 100, 6, pp. $649-669$.

[22] Astratenkova I.V., Ragozkin V.A. Signal ways, which take part in skeletal muscles protein metabolism regulation. . Russian physiological journal named after I.M. Sechenova. 2016, vol. 102, 7, pp. 753 - 772.

[23] Seluyanov V.N. Training average distance runners. Moscow: SportAkademPress. 2001, 104.

[24] Igor V. Zub, Victor A. Kurys, Andrey V. Akimenko. Physical upbringing and rowing and sailing training in naval and nautical educational establishments of Russia. Russian Journal of Physical Education and Sport. 2019, vol. 14(1), pp. 137-143. DOI: 10.14526/2070-4798-2019-14-1-159-167.

[5] Fudin N.A., Vagin Y.E., Pigareva S.N. System mechanisms of tiredness during physical loads of cyclic orientation. New medical technologies Bulletin. 2014, vol. 21, 3, pp. 118 - 121. DOI: 10.12737/5915

[6] Slepova D.A., Kalinin A.V. Physical load of submaximal power influence on a regional blood flow among highly-qualified athletes of cyclic kinds of sport. Scientific notes of P.F. Lesgaft University. 2016, 7(137), pp. $128-133$.

[7] Rakhmanov R.S., Sapozhnikova M.A., Blinova T.V., Strakhova L.A., Razgulin S.A., Berezin I.A. Some biochemical indices of energy supply system estimation in an organism during considerable physical loads. Medical almanac. 2015, 1(36), pp. $141-143$.

[8] Baranova E.A., Kapilevich L.V. Functional adaptation of cardiovascular system among athletes, who train in cyclic kinds of sport. Bulletin of Tomsk State University. 2014, 383, pp. 176 - 179.

[9] Solodkov A.S. Peculiarities of tiredness and athletes' rehabilitation. Scientific notes of P.F. Lesgaft University. 2013, 6(100), pp. 131 - 143.

[10] Orlova V.V., Khalaleeva O.E. Organizational-methodical peculiarities of the training process creation in rowing. Modern research of social problems. 2017, vol. 8, 4, pp. 6 - 19. DOI: 10.12731/2218-7405-20174-6-19

[11] Abramova E.F., Nikitina T.M., Kochetkova N.I., Buchina E.V., Yakutkovich N.M., Malkin R.V., Mingazova D.V. Interaction of physical readiness indices and sports result among athletes, who specialize in rowing. Sport science bulletin. 2017, 5, pp. $28-36$.

[12] Myakichenko E.B., Siluyanov V.N. Local muscular endurance development in cyclic kinds of sport. Moscow: TVT Divizion. 2009, 360.

[13] Germanov G.N., Sabirova I.A., Tsukanova E.G. Classificational approach and theoretical notions of special and general in endurance demonstration. Scientific notes of P.F. Lesgaft University. 2014, 2(108), pp. $49-57$.

[14] Mishchenko V., Polishchuk D. Problems and prospects of special endurance development among qualified athletes. Sport science bulletin. 2004, 2, pp. $8-12$.

[15] Panteleeva N.I., Strelnikova S.V., Roshchevskaya I.M. Electrical activity of heart during cardiac ventricles repolarization among athletesswimmers in terms of physical load. Russian physiological journal named after I.M. Sechenova. 2011, vol. 100, 11, pp. 1346 - 1354.

[16] Balykova L.A. Pathogenetic aspects of disadaptive changes in cardiovascular system formation, which are conditioned by intensive physical loads. Bulletin of Mordov University.2016, vol. 26, 3, pp. 336 348. DOI: 10.15507/0236-2910.026.201603.336-348

[17] Popov D.V., Vinogradova O.L., Grigorev A.I. Aerobic working capacity of a person. Moscow: Nauka. 2012, 111.

[18] Shenkman B.S., Litvinova K.S., Gasnikova N.M. and others Creatine as metabolic modulator of skeletal muscles structure and function during power training of a person. Cellular mechanisms. . Russian physiological journal named after I.M. Sechenova. 2006, vol. 92, 1, pp. $100-112$. 